\title{
Kinesin-Like Protein KIF11
}

National Cancer Institute

\section{Source}

National Cancer Institute. Kinesin-Like Protein KIF11. NCI Thesaurus. Code C48872.

Kinesin-like protein KIF11 (1056 aa, 119 kDa) is encoded by the human KIF11 gene. This protein plays a role in the formation of a bipolar spindle during mitosis. 